\title{
Oral health status of fishermen and non-fishermen community of Kutch district, Gujarat, India: a comparative study
}

\author{
Kailash Asawa ${ }^{1}$, Piyush Pujara ${ }^{1}$, Mridula Tak ${ }^{1}$, Ramesh Nagarajappa ${ }^{2}$, Pankaj Aapaliya ${ }^{1}$, \\ Nikhil Bhanushali ${ }^{1}$, Prashant Mishra ${ }^{3}$, Abhishek Sharma ${ }^{4}$ \\ ${ }^{1}$ Department of Public Health Dentistry, Pacific Dental College and Hospital, Debari, Udaipur, Rajasthan, India \\ ${ }^{2}$ Department of Public Health Dentistry, Rama Dental College and Hospital, Kanpur, Uttar Pradesh, India \\ ${ }^{3}$ Department of Public Health Dentistry, Sri Aurobindo Institute of Dental Sciences, Indore, Madhya Pradesh, India \\ ${ }^{4}$ Department of Public Health Dentistry, Government Dental College and Hospital, Jaipur, Rajasthan, India
}

\begin{abstract}
Background: Fishing is one such hazardous occupation, which involves irregular diet, stress, alcoholism, tobacco and pernicious habits. Fishermen have lower socio-economic status and their illiteracy adds to their poor oral hygiene, which may influence general and oral health.

Aim: The aim of the study was to assess and compare the oral health status of fishermen and non-fishermen population of Kutch District, Gujarat, India.

Materials and methods: A descriptive cross-sectional survey was conducted to assess and compare the oral health status of the fishermen and non-fishermen community of Mundra taluka of Kutch district, Gujarat, India, from January 2013 to June 2013.

Results: Fishermen had significantly higher periodontal disease and dental caries than non-fishermen group ( $p=0.001$ ). Malocclusion was significantly higher in non-fishermen group $(p=0.001)$. Extraction was the most prevalent treatment need among both groups. Occupation and educational status were respectively identified as the best predictors for dental caries and periodontal disease.

Conclusions: Findings of the present study suggest that oral health status of the fishermen population was relatively poor, with high caries prevalence and poor periodontal health when compared to the non-fishermen population. In the light of high treatment needs of the study population, health policy that emphasises oral health promotion and prevention would seem more advantageous in addition to traditional curative care.

(Int Marit Health 2014; 65, 1: 1-6)
\end{abstract}

Key words: cross-sectional, fishermen, Kutch, oral health

\section{INTRODUCTION}

Health implies to the relative absence of pain and discomfort and a continuous adaptation and adjustment to the environment to ensure the optimal function. Health is multifactorial, the factors which influence health lie both within the individual and externally in the society, in which he or she lives. It is a truism to say that what man is and to what disease he may fall depends on a combination of 2 sets of factors - his genetic and environmental factors to which he is exposed [1].
Each disease has its unique natural history, which is not necessarily the same in all individuals. Disease results from a complex interaction between the man, the agent and the environment. Disease arises when there is maladjustment of the individual with his environment [1].

The health of workers on a large measure will also be influenced by conditions prevailing at their work place [1]. The example of one such occupation in which the environment plays a major role is fishing. 
Fishingstill remains a hazardous [2] and stressful occupation as it presents difficult physical conditions, dislocation, isolation and less than ideal personal habits [3]. Fishermen have prolonged hours of continuous work, which are found to be correlated with high cigarette and alcohol consumption [4]. Diet lacks fruits and vegetables and meals are eaten at very erratic intervals [5].

Fishermen are prone to excess ultraviolet radiation due to constant exposure to sun [6]. Statistical studies in the past have shown that fishermen are prone to develop skin and lip cancer [7].

Previous studies have shown that subjective symptoms from the musculo-skeletal system are common among fishermen [8]. Crepitations in the shoulder tend to be more common among the fishermen. This indicates heavy dynamic work and prolonged static work [9]. Osteoarthritis of knee among them may result from working and living in the vertical environment of a moving ship [10].

Various studies have shown that high incidence of hypertension may be related to ischaemic heart disease and cerebrovascular illness. This may be influenced by poor eating habits, which include higher sodium intake, accompanying high consumption of salted fish or higher prevalence of tobacco smoking [11], poor health awareness and other social and environmental factors which are common to fishermen [12]. Fluoride levels are also high in some coastal areas and the excessive exposure to them can give increasing number of adverse effects. These may range from mild dental fluorosis to crippling skeletal fluorosis as the level and period of exposure increase. Apart from that, there are reports that excess fluoride consumption promotes cancer, hip fracture, leads to stillbirth or birth defects and has detrimental neurological effects.

Fishing is one such hazardous occupation, which involves irregular diet, stress, alcoholism, tobacco and pernicious habits. Fishermen have lower socio-economic status and their illiteracy adds to their poor oral hygiene, which may influence general and oral health. The access of fishermen to dental services is very limited, making regular check-ups and treatment of caries difficult [13]. Fishermen have poor oral health when compared to that of general population [14].

Kutch is the largest district in India with a total area of $45652 \mathrm{~km}^{2}$. Kutch has $400 \mathrm{~km}$ coastline that constitutes $1 / 4$ of Gujarat's coastline and 1/20 of India's coastline. The Kutch coast and fishing community are not well known in India. The relative remoteness of the Kutch coast and the low social, economic and political power of the fishing community have contributed to this state of affairs [15].

Despite dangerous nature of fishing occupation, very little research have been conducted and reported on fishermen's health and safety. Even in India, the research on this group of population is limited. Therefore the present study was executed to assess and compare the oral health status and treatment needs of fishermen population with non-fishermen population in the coastal region of Kutch, Gujarat, India.

\section{MATERIALS AND METHODS}

\section{STUDY DESIGN, POPULATION AND DURATION}

A descriptive cross-sectional survey was conducted to assess and compare the oral health status of the fishermen and non-fishermen community of Mundra taluka of Kutch District, Gujarat, India, from January 2013 to June 2013.

\section{OFFICIAL PERMISSION AND ETHICAL CLEARANCE}

The study protocol was reviewed by the Ethical Committee of Pacific Dental College and Hospital and the ethical clearance was granted. An official permission was obtained from the Chairman of Fisherfolk community of Kutch District, Gujarat, India.

\section{INFORMED CONSENT}

After explaining the purpose and details of the study, a written informed consent was obtained from all the subjects who were willing to participate.

\section{TRAINING AND CALIBRATION}

Before the commencement of the study, the examiner was standardised and calibrated in the Department of Public Health Dentistry by the Head of Department to ensure uniform interpretations, understanding, and application of the codes and criteria for the diseases to be observed and recorded, and to ensure consistent examination. The examiner first practiced the examination on a group of 10 subjects with a wide range of levels of disease conditions. Then the examiner applied the diagnostic criteria by examining a group of 20 subjects, with full range of disease condition, twice on successive days. The intra-examiner reliability for Decayed Missing Filled Teeth (DMFT) and Community Periodontal Index (CPI) were assessed using Kappa statistics, which were found to be $90 \%$ and $88 \%$, respectively.

\section{INCLUSION AND EXCLUSION CRITERIA}

The exclusion criteria were as follows:

- those who were not willing to participate;

- those who had systemic diseases.

The inclusion criteria were as follows:

- natives belonging to that area/community;

- those who were willing to participate.

\section{PRO FORMA DETAILS}

The pro forma consisted of 3 sections:

1. General information.

2. Information about oral hygiene practices and adverse habits.

3. Clinical parameters (WHO 1997 'Oral Health Assessment Form') [16]. 
General information consisted of demographic data including name, age, gender, date of birth, education and marital status. Information on oral hygiene practices included type of cleaning and materials used for cleaning teeth. Adverse habits included smoking habits and tobacco chewing habits. Clinical parameters assessed were: extra oral examination, temporomandibular joint assessment, oral mucosal lesions, enamel opacities/hypoplasia, dental fluorosis, community periodontal index, loss of attachment, dentition status and treatment needs, prosthetic status and needs, dentofacial anomalies and need for immediate care and referral [16].

\section{PILOT SURVEY}

A pilot study was carried out among 50 fishermen and 50 non-fishermen subjects to determine the feasibility and practicability of the study and the time required for examination of each subject. It helped to know the practical difficulties while conducting the survey. It took around 15-20 min to assess each subject. The prevalence of dental caries, periodontal disease and dentofacial anomalies was found to be $70 \%, 88 \%$ and $40 \%$, respectively for the fishermen group and $50 \%, 55 \%$ and $35 \%$, respectively for the non-fishermen group.

\section{SAMPLING DESIGN}

Multi-stage random sampling was employed to select the study population. Four zones of the Kutch coast are divided as follows:

\begin{tabular}{|c|}
\hline $\begin{array}{l}\text { Zone 1: Bhachau, Gandhidham } \\
\text { Zone 2: Anjar, Mundra } \\
\text { Zone 3: Mandvi, Abdasa upto Jakhau } \\
\text { Zone 4: Abdasa from Jakhau, Lakhpat }\end{array}$ \\
\hline$\downarrow$ \\
\hline Zone 2: Anjar, Mundra block selected randomly \\
\hline$\downarrow$ \\
\hline $\begin{array}{l}\text { Mundra taluka } \\
\text { ( } 8 \text { villages and their } 8 \text { harbours having fishermen po- } \\
\text { pulation) }\end{array}$ \\
\hline$\downarrow$ \\
\hline 2 villages were randomly selected (Bhadreshwar and Luni) \\
\hline$\downarrow$ \\
\hline $\begin{array}{l}2200 \text { subjects (fishermen and non-fishermen) were } \\
\text { randomly selected starting from the reference point }\end{array}$ \\
\hline
\end{tabular}

\section{CLINICAL ASSESSMENT AND DATA COLLECTION}

Clinical examination of the subjects was carried out by the investigator himself. The oral health examination of the subjects was made as described by WHO Oral Health Survey Basic Methods (1997) by using community periodontal probe and plane mouth mirror. Type III clinical examination was followed. Clinical examination was carried out under the adequate natural, broad day light in open premises of houses. On each day 30-35 subjects were examined. A recording clerk who was trained in the recording procedures, assisted in recruiting subjects for the clinical examination and completion of a questionnaire. He was seated close enough to the examiner so that the instruction and codes could be easily heard and the examiner could see that findings were being recorded correctly.

\section{STATISTICAL ANALYSIS}

The recorded data were compiled and entered in a spreadsheet computer program (Microsoft Excel 2007) and then exported to data editor page of SPSS version 15 (SPSS Inc., Chicago, Illinois, USA).

Descriptive statistics included computation of percentages, means and standard deviations. Statistical tests applied for the analysis were Pearson' $\chi^{2}$, t-test, one way analysis of variance and stepwise multiple linear regression analysis. For all the tests, confidence level and level of significance were set at $95 \%$ and $5 \%$, respectively.

\section{RESULTS}

Of the total of 1100 fishermen subjects, 675 (61.3\%) were males and 425 (38.6\%) were females, and out of 1100 non-fishermen subjects, 731 (66.4\%) were males and 369 (33.5\%) were females. The mean age of both fishermen and non-fishermen group was $33.56 \pm 13.40$ (Table 1).

$96 \%$ of the subjects in the fishermen population were Muslims, while majority of the non-fishermen subjects were Hindus ( $n=600 ; 54.5 \%$ ). Higher proportion of participants were married both in fishermen (71\%) and non-fishermen $(65.7 \%)$ groups. Most of participants had an education up to middle level in both fishermen (93.2\%) and non-fishermen (95.2\%) groups.

$24 \%$ and $48 \%$ of the subjects used toothbrush and toothpaste/tooth powder in the fishermen and non-fishermen group, respectively. Majority (43.1\%) of the fishermen used chew sticks for cleaning their teeth in the fishermen group, while majority of non-fishermen (48\%) used toothbrush for teeth cleaning. Males $(50.5 \%$ in the fishermen group and $29.6 \%$ in the non-fishermen group) reported a significantly higher prevalence of adverse oral habits than females (49.2\% in the fishermen group and $27.1 \%$ in the non-fishermen group).

Subjects with ulceration, sores, erosions or fissures of the head, neck and limb region were found to be 151 (13.7\%) and 105 (9.5\%) in the fishermen and non-fishermen groups, respectively. Mild fluorosis was the most prevalent ( $n=275 ; 25 \%$ ) form of dental fluorosis among the fishermen subjects followed by severe fluorosis ( $n=251 ; 22.8 \%$ ). A significant augmentation in dental fluorosis was seen up to 64 years of age. 
Table 1. Distribution of study population by age and gender

\begin{tabular}{|c|c|c|c|c|c|c|}
\hline \multirow[t]{2}{*}{ Age [years] } & \multicolumn{3}{|l|}{ Fishermen } & \multicolumn{3}{|l|}{ Non-fishermen } \\
\hline & Male & Female & Total & Male & Female & Total \\
\hline $5-14$ & 92 (65.2\%) & 49 (34.7\%) & $141(12.8 \%)$ & 66 (79.5\%) & 17 (20.4\%) & 83 (7.5\%) \\
\hline $15-24$ & 17 (40.4\%) & 25 (59.5\%) & 42 (3.8\%) & 87 (65.9\%) & 45 (34\%) & $132(12 \%)$ \\
\hline $25-34$ & $262(62 \%)$ & 160 (37.9\%) & $422(38.3 \%)$ & $240(65.2 \%)$ & $128(34.7 \%)$ & 368 (33.4\%) \\
\hline $35-44$ & $185(61.2 \%)$ & $117(38.7 \%)$ & $302(27.4 \%)$ & 220 (66.4\%) & $111(33.5 \%)$ & 331 (30\%) \\
\hline $45-54$ & $78(66.6 \%)$ & 39 (33.3\%) & 117 (10.6\%) & $86(67.1 \%)$ & 42 (32.8\%) & $128(11.6 \%)$ \\
\hline $55-64$ & 16 (59.2\%) & $11(40.7 \%)$ & 27 (2.4\%) & $19(46.3 \%)$ & $22(53.6 \%)$ & 41 (3.7\%) \\
\hline $65-74$ & 25 (51\%) & 24 (48.9\%) & 49 (4.4\%) & $13(76.4 \%)$ & 4 (23.5\%) & 17 (1.5\%) \\
\hline Total & $675(61.3 \%)$ & 425 (38.6\%) & $1100(100 \%)$ & 731 (66.4\%) & 369 (33.5\%) & 1100 (100\%) \\
\hline Mean age \pm SD & $33.35 \pm 13.38$ & $33.89 \pm 13.44$ & $33.56 \pm 13.40$ & $32.71 \pm 13.79$ & $35.24 \pm 12.43$ & $33.56 \pm 13.40$ \\
\hline
\end{tabular}

Calculus and shallow pockets (4-5 mm) were demonstrated among $25 \%$ and $26.5 \%$ of the study subjects, respectively in the fishermen group, while in the non-fishermen group it was found to be $14.3 \%$ and $8.6 \%$, respectively. In both groups the study subjects evidenced highest prevalence of deep pockets (6-8 $\mathrm{mm}$ ) among older age groups (28.5\% and $23.5 \%$, respectively). Overall, fishermen had significantly higher periodontal disease than non-fishermen group (Table 2).

6-8 $\mathrm{mm}$ and 9-11 $\mathrm{mm}$ of loss of attachment was evidenced by $27.8 \%$ and $25.8 \%$ of the fishermen, respectively. In the non-fishermen group the proportion was $8.8 \%$ and $8.3 \%$, respectively. Loss of attachment of $6-8 \mathrm{~mm}$ and 9-11 mm was significantly higher in prevalence among males ( $p=0.01$ ) in the fishermen group. Loss of attachment was also significantly higher in the fishermen group than non-fishermen group ( $p=0.001$ ) (Table 2).

Around $30.3 \%$ fishermen subjects and $20.3 \%$ non-fishermen subjects had mild dental caries. In the fishermen population, significantly $(p=0.001)$ males were having higher moderate and severe dental caries scores than females. Fishermen population showed significantly greater proportion of subjects with dental caries (82.6\%) as compared to non-fishermen population (44.6\%) $(p=0.001)$ (Table 2).

Extraction was the most prevalent treatment need among both groups (fishermen group: $n=726 ; 66.2 \%$, non-fishermen group: $n=420 ; 38.2 \%)$, followed by pulp care and restoration, 1 surface filling, and 2 surface filling. Fishermen had significantly higher number of treatment needs as compared to non-fishermen ( $p=0.001$ ).

Around $62.9 \%$ of the fishermen subjects and $59.5 \%$ of the non-fishermen subjects had no abnormality or minor malocclusion with no or slight orthodontic treatment need. Very severe malocclusion was significantly evident among $18.5 \%$ of the fishermen and $9 \%$ of the non-fishermen subjects (Table 2).
The best predictors in the descending order for DMFT were: occupation, educational status, age, oral hygiene practices and marital status, with variances of $39.1 \%$, $39.9 \%, 40.3 \%, 40.6 \%$ and $40.8 \%$, respectively. The best predictors in the descending order for CPI were: occupation, educational status, oral hygiene practices and gender, with variances of $13.2 \%, 13.7 \%$, and $14.2 \%$, and $14.5 \%$, respectively (Tables 3,4 ).

\section{DISCUSSION}

The use of toothbrush was limited to $24 \%$ of the fishermen population. This finding is in concordance with the findings of Kumar at el. [17], but is analogous to the results reported by Sakthi et al. [18] at Chennai, India, where 76.9\% of building construction workers used toothbrush and toothpaste for cleaning their teeth.

The present study demonstrated that the prevalence of tobacco usage was increasing subsequently with age. Townsend et al. [19] also portrayed a similar pattern and attributed this finding to the fact that young people generally have relatively low incomes with a high proportion of it available for discretionary expenditure, so that changes in income are more likely to affect their tobacco consuming patterns. The extra oral clinical conditions depicted in the present study were ulcerations, sores, erosions and fissures, the highest prevalence being depicted in head, neck and limbs region (13.7\%). This is in accordance with the results of the study conducted by Bhat [20] on rural Indian fishing community residing in coastal areas of Karnataka. This relatively high prevalence of ulceration may be attributed to the excess ultraviolet radiation due to constant exposure to sun.

The present study elicited the absence of dental fluorosis among $16.1 \%$ of the fishermen subjects, revealing $76 \%$ subjects with dental fluorosis, and the rest was excluded. This high prevalence of fluorosis is attributed to high water fluoride level in Kutch district [21]. As demonstrated 
Table 2. Distribution of the study subjects according to Community Periodontal Index (CPI), loss of attachment, Decayed Missing Filled Teeth (DMFT) and Dental Aesthetic Index (DAl) scores

\begin{tabular}{|c|c|c|c|}
\hline Variables & Fishermen & $\begin{array}{l}\text { Non- } \\
\text {-fishermen }\end{array}$ & $\mathbf{P}$ \\
\hline \multicolumn{2}{|c|}{ Community Periodontal Index scores: } & & $0.001 *$ \\
\hline Healthy & $141(14.6 \%)$ & $596(54.1 \%)$ & \\
\hline Bleeding & $142(12.9 \%)$ & $177(16 \%)$ & \\
\hline Calculus & $264(25 \%)$ & $158(14.3 \%)$ & \\
\hline Pocket (4-5 mm) & $292(26.5 \%)$ & $95(8.6 \%)$ & \\
\hline Pocket (6 mm or more) & $227(20.6 \%)$ & $67(6.2 \%)$ & \\
\hline Excluded sextant & $14(1.2 \%)$ & $10(0.9 \%)$ & \\
\hline Loss of attachment: & & & $0.001 *$ \\
\hline $0-3 \mathrm{~mm}$ & $215(19.5 \%)$ & $643(58.4 \%)$ & \\
\hline $4-5 \mathrm{~mm}$ & $322(29.2 \%)$ & $176(16 \%)$ & \\
\hline $6-8 \mathrm{~mm}$ & $306(27.8 \%)$ & $97(8.8 \%)$ & \\
\hline $9-11 \mathrm{~mm}$ & $274(25.8 \%)$ & $92(8.3 \%)$ & \\
\hline $12 \mathrm{~mm}$ or more & $3(0.2 \%)$ & $3(0.2 \%)$ & \\
\hline Excluded sextant & $14(1.2 \%)$ & $14(0.9 \%)$ & \\
\hline Dental caries status: & & & $0.001 *$ \\
\hline None $(0)$ & $192(17.4 \%)$ & $610(55.4 \%)$ & \\
\hline Mild (0.1-2.6) & $308(28 \%)$ & $105(9.5 \%)$ & \\
\hline Moderate (2.7-4.5) & $334(30.3 \%)$ & $224(20.3 \%)$ & \\
\hline Severe $(>4.5)$ & $266(24.1 \%)$ & $157(4.2 \%)$ & \\
\hline Dental Aesthetic Index: & & & $0.001 *$ \\
\hline $\begin{array}{l}\text { No abnormality or } \\
\text { minor malocclusion } \\
\text { No/slight need }\end{array}$ & 381 (62.9\%) & 347 (59.5\%) & \\
\hline $\begin{array}{l}\text { Definite malocclusion } \\
\text { Elective treatment }\end{array}$ & 73 (12\%) & $110(18.8 \%)$ & \\
\hline $\begin{array}{l}\text { Severe malocclusion } \\
\text { Highly desirable }\end{array}$ & 39 (6.4\%) & 73 (12.5\%) & \\
\hline $\begin{array}{l}\text { Very severe or handi- } \\
\text { capping malocclusion } \\
\text { Mandatory }\end{array}$ & $112(18.5 \%)$ & $53(9 \%)$ & \\
\hline
\end{tabular}

Test applied Chi-square test; *statistically significant at $p \leq 0.05$

Table 3. Stepwise multiple linear regression analysis with Decayed Missing Filled Teeth (DMFT) as a dependent variable

\begin{tabular}{lllll}
\hline Model & $\mathbf{R}$ & $\mathbf{R}^{\mathbf{2}}$ & $\mathbf{F}$ & $\mathbf{P}$ \\
\hline 1 & $0.625(\mathrm{a})$ & 0.391 & 1376.179 & $0.000(\mathrm{a})$ \\
2 & $0.631(\mathrm{~b})$ & 0.399 & 711.73 & $0.000(\mathrm{~b})$ \\
3 & $0.635(\mathrm{c})$ & 0.403 & 481.97 & $0.000(\mathrm{c})$ \\
4 & $0.637(\mathrm{~d})$ & 0.406 & 366.31 & $0.000(\mathrm{~d})$ \\
5 & $0.638(\mathrm{e})$ & 0.408 & 294.82 & $0.000(\mathrm{e})$
\end{tabular}

a - predictors: (constant), occupation; $b$ - predictors: (constant), occupation, educational status; $\mathrm{c}-$ predictors: (constant), occupation, educational status, age; $d$ - predictors: (constant), occupation, educational status, age, oral hygiene practices; e - predictors: (constant), occupation, educational status, age, oral hygiene practices, marital status
Table 4. Stepwise multiple linear regression analysis with Community Periodontal Index (CPI) as a dependent variable

\begin{tabular}{lllll}
\hline Model & $\mathbf{R}$ & $\mathbf{R}^{\mathbf{2}}$ & $\mathbf{F}$ & $\mathbf{P}$ \\
\hline 1 & $0.364(\mathrm{a})$ & 0.132 & 326.99 & $0.000(\mathrm{a})$ \\
2 & $0.370(\mathrm{~b})$ & 0.137 & 170.08 & $0.000(\mathrm{~b})$ \\
3 & $0.377(\mathrm{c})$ & 0.142 & 118.57 & $0.000(\mathrm{c})$ \\
4 & 0.381 (d) & 0.145 & 91.11 & $0.000(\mathrm{~d})$
\end{tabular}

a - predictors: (constant), occupation; $b$ - predictors: (constant), occupation, educational status; $\mathrm{c}$ - predictors: (constant), occupation, educational status, oral hygiene practices; $\mathrm{d}$ - predictors: (constant), occupation, educational status, oral hygiene practices, gender

in a previous study [22], the prevalence and severity of dental fluorosis is directly related to the amount of fluoride ingested, age at the time of exposure and duration of the exposure; the present study population needs further investigation in this aspect.

In the present study, the fishermen group showed $85.4 \%$ prevalence of periodontal disease with only $0.23 \pm 0.01$ healthy sextants per person. The prevalence of periodontal disease in the fishermen group was similar to that obtained in the National Oral Health Survey and Fluoride mapping 2002-2003 of India [23] (89.6\% in 35-44 years), and Gujarat [24] (83.7\% in 35-44 years age groups), respectively. The predictors for periodontal disease as identified by the stepwise linear regression were: occupation, educational status, oral hygiene practices and gender. Occupation was found to be the best predictor for periodontal diseases, which may be attributed to the fact that majority of fishermen had low educational status, poor oral hygiene practices and increased tobacco consumption.

In the present study, the prevalence of dental caries was $82.6 \%$ among the fishermen group, which was found to be higher than the non-fishermen group (45.2\%). Findings among the fishermen group are higher to those studies conducted by Kumar et al. in 2009 [17] (78.6\%) and Bhat in 2008 [20] (78\%). A probable explanation to this may be barriers related to the fishermen group like poor oral hygiene practices, lack of awareness, affordability and lack of oral health care. In spite of better oral hygiene, mean Decayed Teeth was found to be higher among females. Lukacs [25] cited in his meta-analysis that in addition to the negative influences of female sex hormones and changes in physiology and behaviour associated with pregnancy, multiple social and religious factors may contribute to the sex difference in oral health in South Asia. The predictors for dental caries, as observed in the present study, were: occupation, educational status, age, oral hygiene practices and marital status. These findings may be attributed to the facts like isolation of the villages, lack of transportation, irregular diet, stress, alcoholism, tobacco and pernicious habits impose limitations on the availability of health professionals to 
provide dental services, as well as the unavailability of oral hygiene maintenance materials [26].

The most required treatment in the fishermen group was extraction (66\%), followed by pulp care and restoration (63.9\%) and 1 surface filling (27.9\%). These findings are similar to studies conducted by Kumar et al. [17], Bhat [20], and Bali et al. [24] in the state of Gujarat. It has been seen that people in developing countries usually have limited access to dental care, more periodontal disease and higher levels of plaque and calculus than people in more economically developed societies. This was certainly true for the present study group for whom dental health services were virtually non-existent.

The degree of malocclusion was higher among the non -fishermen (40.5\%) compared to the fishermen (27.1\%). The difference in Dental Aesthetic Index scores and orthodontic treatment needs may be ascribed to racial variation, different age ranges, genetic predisposition, cross-cultural differences in living standards and variations in growth and facial skeleton development and occlusion.

The workplace environment of individuals has an influence on their oral health status through their behaviour and habits exerted by their personal and work characteristics. The cumulative lifetime exposure to oral health promoting or oral health damaging environments are most accurate explanations for observed oral health differences between the population groups.

The nature of this study was cross-sectional, thus precluding the ability to draw inferences about causal relationships. Secondly, the duration of exposure of adverse habits was not assessed in the present study. Therefore further research are required involving longitudinal study on the same target population impinging the risk factors involved in the causation of oral disease.

\section{CONCLUSIONS}

Findings of the present study suggest that oral health status of fishermen population was relatively poor with high caries prevalence and poor periodontal health when compared to the non-fishermen population. In the light of high treatment needs of the study population, health policy that emphasises oral health promotion and prevention would seem more advantageous in addition to traditional curative care.

\section{ACKNOWLEDGEMENTS}

The authors would like to thank the study participants for their participation and kind cooperation throughout the study.

\section{REFERENCES}

1. Park K. Park's textbook of preventive and social medicine. $19^{\text {th }}$ ed. Banarasidas Bhanot Publishers, Jabalpur 2008.

2. Roberts SE. Hazardous occupations in Great Britain. Lancet 2002; 360: 543-544.

3. Carel RS, Carmil D, Keinan G. Occupational stress and well-being: do seafarers harbor more health problems than people on the shore? Isr J Med Sci 1990; 26: 619-624.
4. Casson FF, Zucchero A, Boscolo Bariga A et al. Work and chronic health effects among fishermen in Chioggia, Italy. $G$ Ital Med Lav Ergon 1998; 20: 68-74.

5. Lawrie T, Matheson C, Ritchie L, Murphy E, Bond C. The health and lifestyle of Scottish fishermen: a need for health promotion. Health Educ Res 2004; 19: 373-379.

6. Mahajan BK, Gupta MC. Textbook of preventive and social medicine. $3^{\text {rd }}$ Ed. Jaypee Brothers Medical Publishers Pvt. Ltd., New Delhi 1992.

7. Shambaugh Ph. Tar cancer of the lip in fishermen. Jour. A.M.A. 1935; 104: 2326-2329.

8. Torner M, Zetterberg C, Hansson T, Lindell V, Kadefors R. Musculo -skeletal symptoms and signs and isometric strength among fishermen. Ergonomics 1990; 33: 1155-1170.

9. Torner M, Zetterberg C, Anden U, Hansson T, Lindell V. Workload and musculoskeletal problems: A comparison between welders and office clerks. Ergonomics 1991; 34: 1179-1196.

10. Pearce MS, Buttery YE, Brueton RN. Knee pathology among seafarers: a review of 299 patients. Occup Med (Lond) 1996; 46: 137-140.

11. Schloss I, Kidd MS, Tichelaar HY, Young GO, O'Keefe SJ. Dietary factors associated with a low risk of colon cancer in coloured west coast fishermen. S Afr Med J 1997; 87: 152-158.

12. Kirkutis A, Norkiene S, Griciene P, Gricius J, Yang S, Gintautas J. Prevalence of hypertension in Lithuanian mariners. Proc West Pharmacol Soc 2004; 47: 71-75.

13. Saarni U, Saarni H. Xylitol for mess rooms: a method worth trying to prevent caries among seafarers. Bull Inst Marit Trop Med Gdynia 1997; 48: 91-97.

14. Sandbeek. OW. Dental health status and use of dental services among seamen in overseas trade. Nor Tannlaegeforen Tid 1977; 87: 275-281.

15. Gulf of Kutch. Available at: http://en.wikipedia.org/wiki/Gulf_of_ Kutch [Accessed on 25th April 2013].

16. World Health Organization. Oral health surveys. Basic methods. $4^{\text {th }}$ Ed. WHO, Geneva 1997: 36-51.

17. Kumar TS, Dagli RJ, Mathur A et al. Oral health status and practice of dentate Bhil adult tribes of Southern Rajasthan, India. Int Dent J 2009; 59: 133-140.

18. Sakthi SS, John J, Saravanan S, Kumar RP. Periodontal health status and treatment needs among building construction workers in Chennai, India. J Int Oral Health 2011; 3: 7-14.

19. Townsend J, Roderick P, Cooper J. Cigarette smoking by socioeconomic group, sex, and age: effects of price, income, and health publicity. BMJ 1994; 309: 923-927.

20. Bhat M. Oral health status and treatment needs of a rural Indian fishing community. West Indian Med J 2008; 57: 414-417.

21. Water and Sanitation Management Organization, Gujarat. Available at: www.wasmo.org. [Accessed on 07-05-2013].

22. Thylstrup A, Fejerskov 0 . Clinical appearance of dental fluorosis in permanent teeth in relation to histological changes. Community Dent Oral Epidemiol 1978; 6: 315-328.

23. Bali RK, Mathur VB, Talwar PP, Chanana HB. National Oral Health Survey and Fluoride Mapping 2002-2003 India. Dental Council of India and Ministry of Health and Family Welfare (Government of India), 2004.

24. Bali RK, Mathur VB, Talwar PP, Chanana HB. National Oral Health Survey and Fluoride Mapping 2002-2003 Gujarat. Dental Council of India and Ministry of Health and Family Welfare (Government of India), 2004.

25. Lukacs JR. Sex differences in dental caries experience: clinical evidence, complex etiology. Clin Oral Investig 2011; 15: 649-656.

26. Varenne B, Petersen PE, Ouattara S. Oral health status of children and adults in urban and rural areas of Burkina Faso, Africa. Int Dent J 2004; 54: 83-88 